\title{
Electrical Resistivity Based Empirical Model for Predicting Cassava Plant (TMS 98/0505) Tuber Yield on Sandy-loam Soil
}

\author{
E. O. Joshua ${ }^{1}$, A. O. Mokuolu ${ }^{2}$ \\ ${ }^{1}$ Department of Physics, University of Ibadan, Ibadan, Oyo state, Nigeria \\ ${ }^{2}$ Department of Physics, Federal College of Education, Abeokuta, Ogun state, Nigeria
}

\begin{abstract}
This study examined the effectiveness of soil electrical resistivity (ER) as a tool for tuber yield prediction. Electrical Resistivity survey was conducted on sandy-loam soil from the soil surface at $0-0.3 \mathrm{~m}\left(\mathrm{ER}_{30}\right)$ and $0-0.9 \mathrm{~m}\left(\mathrm{ER} \mathrm{R}_{90}\right)$ depths using multielectrode Wenner array and Miller $400 D$ resistance meter. After ER survey, Cassava plants' stem cuttings each $0.25 \mathrm{~m}$ long were planted on the soil using standard methods. Twelve 12 months after, tuber yield parameters: number of cassava tuber $\left(N_{T}\right)$, average tuber length $\left(T_{L}\right)$ and tuber weight $\left(T_{W}\right)$ were measured on cassava plants whose soil ER has been measured. The results indicated that ER correlates insignificantly with $N_{T}(r=-0.05)$ and $T_{L}(r=0.04)$. ER $R_{90}$ also correlates insignificantly with $T_{W}(r=-0.03)$ while ER $R_{30}$ correlates significantly with $T_{W}(r=-0.84)$. Lower $E R_{30}$ areas exhibited higher yield than higher $E R_{30}$ areas. Soil ER $R_{30}$ between 250 and $500 \Omega m$ supports $T_{W}$ better than $E R_{30}>500 \Omega m$. The relationship between $E R_{30}$ and $T_{W}$ was best fitted to Lorentz $\left(R^{2}=0.85\right)$, Gauss $\left(R^{2}=0.84\right)$ and Boltzmann $\left(R^{2}=0.82\right)$ distributions.
\end{abstract}

Keywords: electrical resistivity, empirical model, sandy-loam soil, cassava tuber yield, wenner array

\section{Introduction}

Soil ER prospecting is one of the most attractive geophysical methods in agricultural fields application, offering a non destructive tool for describing the subsurface properties over a large range of scales without digging as compared to classical soil science measurements and observations which perturb the soil by random or regular drilling and sampling [18], [24]. Soil ER mapping with limited depth resolution but good area cover is an emerging tool for mapping variations in physico-chemical soil parameters for precision agriculture [16], [10]. This is because ER is related to several soil properties and electrical survey information; it therefore represents a rapid and flexible tool to predict spatial soil variability at the field or local scale [27]. Resistivity techniques is inexpensive in terms of cost and time compared to direct pitting method, and supplies reliable subsurface information over depth ranges that are much greater than the depth ranges of direct pitting techniques [21].

Cassava, on the other hand, is a major staple food in developing world like Nigeria, providing a basic diet for around 500 million people. This explains why electrical resistivity (ER) studies for agricultural productivity such as in Cassava plants are very important. Cassava plants, despite its popularity as one of the most widely cultivated plants in the world [23], the yields are limited by the fertility status [25] of the soil on which they are planted. It therefore requires thorough study especially with a tool like soil ER which provides information on the soil conditions or fertility level needed to improve its quality and yield.

Studies that use ER of soil in mapping cassava plant growth and yield are very scarce. This therefore necessitates the need for research studies in this area especially to help predict cassava plants' yield. The aim of this study is to develop an empirical relationship which uses soil ER to predict cassava plants' tuber yield.

\section{Literature Survey}

Field mapping of electrical resistivity [9], [28] or its reciprocal, electrical conductivity [14], [19] are used for predicting soil properties or precision farming applications. Electrical resistivity of soil because of its sensitivity to soil properties like water [17], [11] has been used at the field scale [10] for agricultural management, especially in precision agriculture [20], [14], [7]; study of soil - plant system, root distribution and quantification mapping [4], [5], [6], [12], [26]; Soil texture mapping [30]; soil hydraulic conductivity [15] and in assessing the effect of different tillage systems [8].

In a study of physical-chemical properties of soils for Jawar crop, [22] observed soil ER values within the range 135 $155 \mathrm{k}-\Omega-\mathrm{cm}$ to be suitable for plants' growth on sandy loam soils. Zones of increased ER were observed underneath plants by [29] and were attributed to soil drying and/ or plants' uptake of dissolved ions by the roots. Changes in ER observed in the study were clearly linked to differences in plant growth and irrigation quantities. According to [21] soil with ER values $37-511 \Omega \mathrm{m}$ was observed as a probable site for optimum cocoa yield, while sites graded into sandy substratum with topsoil ER values 126 - 2,306 $\Omega \mathrm{m}$ are not quite suitable for cocoa production. In a study of ER against vine trunk circumference (girth) and crop yield, [27] found that ER showed structure variability that matched well with trunk circumference spatial pattern and yield. In the study correlations were found between ER and plant variables (trunk circumference and production) with the first soil layer $(0-0.5 \mathrm{~m})$ having the highest correlations. The topsoil ER was negatively correlated to trunk circumference $(\mathrm{r}=0.40, \mathrm{p}$ $<0.05)$ and yield $(\mathrm{r}=-0.40, \mathrm{p}<0.05)$. They inferred that

Volume 5 Issue 6, June 2016 


\section{International Journal of Science and Research (IJSR) \\ ISSN (Online): 2319-7064}

Index Copernicus Value (2013): 6.14 | Impact Factor (2015): 6.391

since the spatial patterns identified with ER correlated with the plant attributes, then the spatial patterns of both ER and the chosen plant parameters are strongly dependent on permanent soil features (i.e soil texture etc), whose position and contours exhibit little or no changes over time. In another study by [13], a significant relationship was found between soil ER and root mass density of coffee trees. In the study, spatial distribution of ER closely matched the spatial pattern of root mass density of the coffee trees with highest ER values found at $0.1-0.3 \mathrm{~m}$ soil layer and low values at deeper soil layers. According to [26], areas of large ER values (up to $460 \Omega \mathrm{m}$ ) was also found close to tree trunks and variability in ER was related to root biomass density in orchard. ER values have been observed to show variations in different soil layers. According to some studies, ER values were observed to be lower at the deep soil layers when compared to those at the top ones [18], [22], [13].

\section{Problem Definition}

Traditional method of soil analyses for yield and soil fertility determination requires collection of soil samples, transportation of samples to the laboratory and laboratory analysis. These methods are laborious, time consuming and expensive [2], [3]. In addition, inadequate sampling density, high cost of convectional soil sampling and analysis may prevent soil property segregation and classification [1]. This may then rendered useless the information obtained from soil samples when correlated with yield or if not, may just provide very minor contributions.

Thus, there is a need for another means such as electrical resistivity method which is non-destructive, easier, less time consuming [14], least expensive [1], spatially continuous and well adequate for monitoring soil fertility and estimating plant yield.

\section{Methodology}

\subsection{Study Area}

The study was conducted at an experimental field located within the farm settlement area of Federal College of Education, Osiele, Abeokuta. Osiele is located $54 \mathrm{~km}$ west of Ibadan between latitude $7^{\circ} 11^{\prime} \mathrm{N}$ and longitude $3^{\circ} 27^{\prime} \mathrm{E}$, and at altitude $148 \mathrm{~km}$ in Odeda Local Government area, Abeokuta, Ogun State. The mean rainfall is about $80 \mathrm{~mm}$, ranging between $0.5 \mathrm{~mm}$ and $81.1 \mathrm{~mm}$ while the average temperature ranged between $16^{\circ} \mathrm{C}$ and $38^{\circ} \mathrm{C}$. The field is made up of sandy-loam soil, measures $50 \mathrm{~m}$ by $135 \mathrm{~m}$ in dimension, and $0.7 \mathrm{Ha}$ in size. The field is also made up of two parts: the southern part (section 1) and the northern part (section 2). Section 1 part of the field had been used for maize and cassava cultivation in the preceding years while section 2 had been left uncultivated for some years.

\subsection{Land Preparation and Layout}

The field was cleared and a $5 \mathrm{~m}$ boarder spacing was made around the field. The remaining field space which measures $40 \mathrm{~m}$ in width and $125 \mathrm{~m}$ in length was then used as the planting area. The planting area was pegged and lined into 125 horizontal rows / traverses (55 rows in section 1 and 70 rows in section 2) along which electrical resistivity (ER) survey are to be taken and cassava stems are to be planted Each horizontal row (traverse) measures $40 \mathrm{~m}$ in length, with a separation distance of $1 \mathrm{~m}$ between one traverse and another.

Section 1 then measures $40 \mathrm{~m}$ by $55 \mathrm{~m}$ while section 2 measures $40 \mathrm{~m}$ by $70 \mathrm{~m}$ in dimension. The discarded $5 \mathrm{~m}$ spacing on all sides of the field is to prevent cross pollination from surrounding plants and ensure easy access and passage onto the field during observation, and measurements of soil ER and yield data collection.

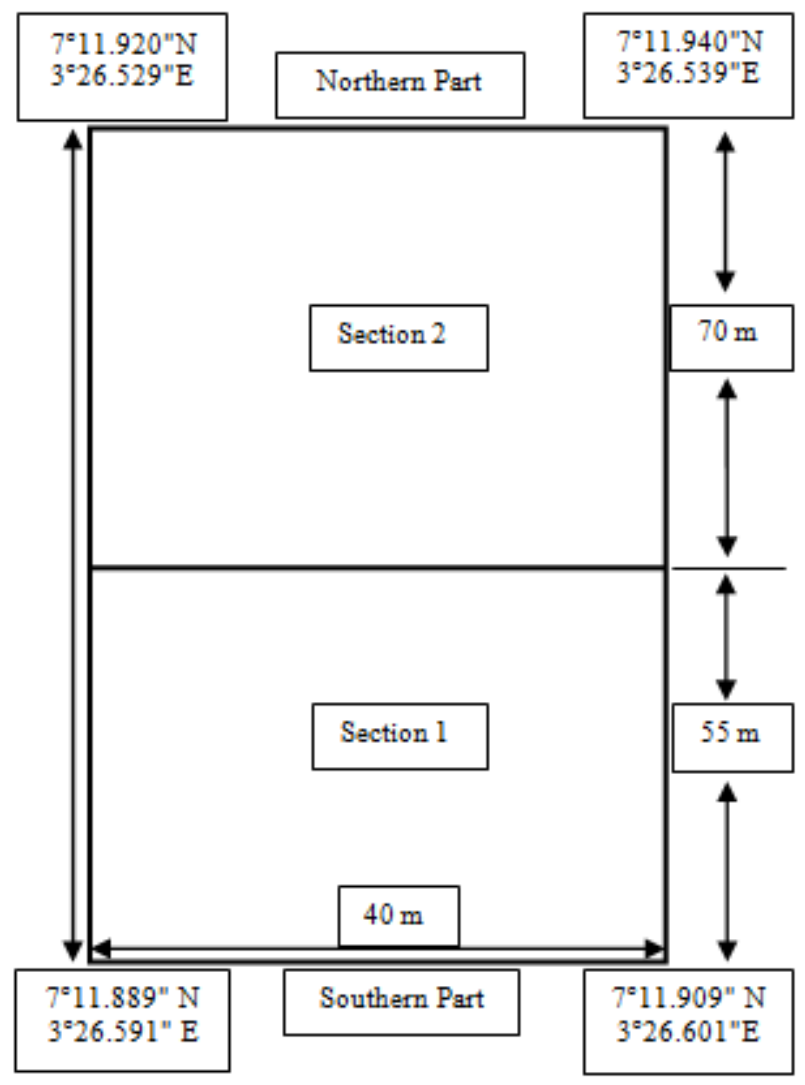

Figure 1: Schematic diagram of the planting area

\subsection{Measurement of Soil Electrical Resistivity (ER)}

Electrical resistivity (ER) survey were conducted from the soil surface at $0-0.3 \mathrm{~m}$ and $0-0.9 \mathrm{~m}$ soil depths along the traverses (horizontal rows) using Miller 400D resistance meter. The resistance meter uses two pairs of electrodes (two current and two potential electrodes) connected via four insulated single-core copper wire cables and measures the average electrical resistance of the soil to a depth equal to the electrode spacing (a) using the principle of Wenner electrode configuration.

The electrodes were equally spaced along a line (traverse) on the soil surface at a distance of $0.3 \mathrm{~m}$ between the electrodes for ER survey at $0-0.3 \mathrm{~m}$ soil depth and distance $0.9 \mathrm{~m}$ between the electrodes for ER survey at $0-0.9 \mathrm{~m}$ soil depth. Electrical current (I) was introduced into the soil through the current electrodes at the soil surface and the potential difference $(\mathrm{V})$ due to the current flow was then measured between the pair of potential electrodes. The meter then displays the result as average soil resistance $(\mathrm{R})$. The 


\section{International Journal of Science and Research (IJSR) ISSN (Online): 2319-7064}

Index Copernicus Value (2013): 6.14 | Impact Factor (2015): 6.391

actual point of resistance being measured in the soil is the midpoint between the potential electrodes. For Wenner array, the soil resistivity, ER is calculated using:

$$
E R=\frac{2 \pi a \Delta V}{I}=2 \pi a R(1.0)
$$

The ER survey was conducted on a total of 42 traverses (made up of 19 traverses in section 1 and 23 traverses in section 2), taken at thirteen (13) different points along each traverse (as shown by Fig. 2). The distance between one ER survey point and another along each traverse is $3 \mathrm{~m}$. The separation distance between one ER survey traverse and another is also $3 \mathrm{~m}$. Soil ER measured from $0-0.3 \mathrm{~m}$ soil depth is called shallow ER $\left(\mathrm{ER}_{30}\right)$ while ER measured from $0-0.9 \mathrm{~m}$ soil depth is called deep ER $\left(\mathrm{ER}_{90}\right)$. In total, 546 $\mathrm{ER}_{30}$ and $546 \mathrm{ER}_{90}$ data were taken for the whole field.

\subsection{Cassava Planting and Weeding}

After ER survey, Cassava (TMS 98/0505) cuttings each 0.25 $\mathrm{m}$ long were planted along the rows at $1 \mathrm{~m} \mathrm{x} 1 \mathrm{~m}$ spacing and inclination angle of $45^{\circ}$ such that about half the length of each cutting were buried into the soil. A total of 5,000 cassava stems were planted on 125 rows such that each row contains 40 planted cassava stems.

Pre-emergence (atrazine) and post-emergence (grammazone) herbicides were sprayed according to standard practices, onto the field immediately after planting to curb the growth of weeds that might compete with the plants during their germination. Weeds were also controlled according to standard practices, through manual weeding in the first 6 weeks ( $1 \frac{1}{2}$ months) after planting and subsequently by application of herbicides every 3 months till the plant reach maturity.

\subsection{Collection of Cassava tuber yield data}

Twelve (12) months after planting (plant maturity), tuber yield parameters: number of cassava tuber $\left(\mathrm{N}_{\mathrm{T}}\right)$, average length of cassava tuber $\left(\mathrm{T}_{\mathrm{L}}\right)$ and cassava tuber weight $\left(\mathrm{T}_{\mathrm{W}}\right)$ were measured on cassava plants whose soil ER have also been measured. The number of cassava tuber $\left(\mathrm{N}_{\mathrm{T}}\right)$ produced per plant were counted and recorded. Measuring tapes were used for measuring $T_{L}$ while $T_{W}$ was measured using a weighing balance.

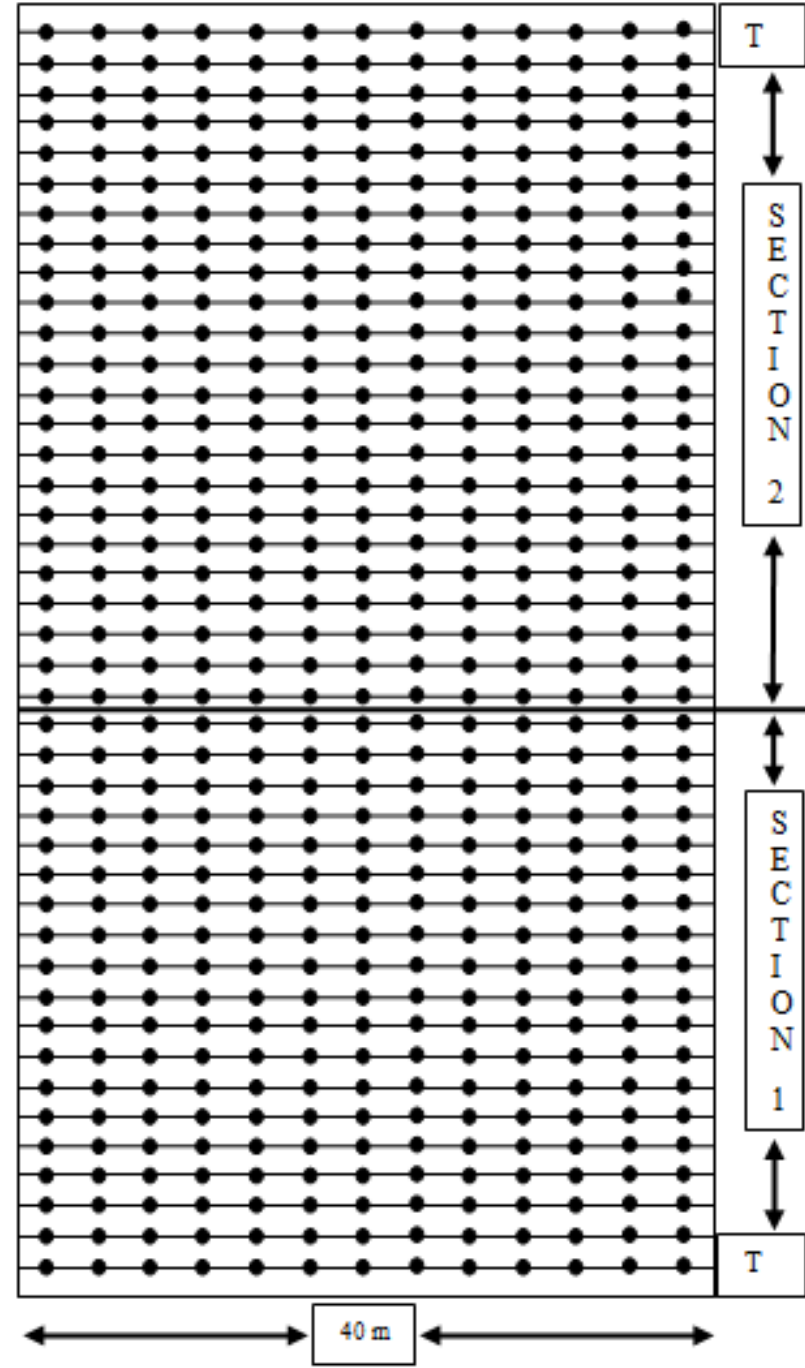

Figure 2: Shape and ER survey points across the study field. The black dots represent ER measurement points while the horizontal row represents the measurement traverse, $\mathrm{T}$.

\subsection{Data Analysis}

Statistical analysis such as mean, standard deviation, coefficient of variation (CV) and correlation analysis were used for analyzing the collected data with the aid of OriginPro 8.1 and SPSS 21.0 statistical softwares. Curve estimation (Lorentz, Gauss and Boltzmann distributions; exponential decay, linear, logarithm, spherical, quadratic, cubic, and power curves) analysis were performed to determine the best fit relationship between ER and tuber yield parameters.

\section{Results and Discussion}

\subsection{Spatial distribution of soil resistivity, ER}

A total of $540 \mathrm{ER}\left(\mathrm{ER}_{30}\right.$ and $\left.\mathrm{ER}_{90}\right)$ data were used for analysis, instead of $546 \mathrm{ER}$ data collected. This is because some ER data were excluded due to missing cassava plants on points where they were measured. 


\section{International Journal of Science and Research (IJSR) \\ ISSN (Online): 2319-7064}

Index Copernicus Value (2013): 6.14 | Impact Factor (2015): 6.391

Table 1: Basic Statistical description of ER data

\begin{tabular}{|c|c|c|c|c|}
\hline & \multicolumn{2}{|c|}{$\begin{array}{c}\mathrm{ER}_{30}(\Omega \mathrm{m}) \\
(0-0.3 \mathrm{~m} \text { depth }) \\
\end{array}$} & \multicolumn{2}{|c|}{$\begin{array}{c}\mathrm{ER}_{90}(\Omega \mathrm{m}) \\
(0-0.9 \mathrm{~m} \text { depth })\end{array}$} \\
\hline & Section 1 & Section 2 & Section 1 & Section 2 \\
\hline Min & 380.43 & 143.06 & 620.04 & 316.67 \\
\hline Max & $3,065.60$ & $1,419.85$ & $67,781.23$ & $455,766.71$ \\
\hline Mean & 982.53 & 573.54 & $7,962.93$ & $8,062.65$ \\
\hline $\mathrm{CV}$ & 0.36 & 0.35 & 1.74 & 3.44 \\
\hline & $\mathrm{N}=241$ & $\mathrm{~N}=299$ & $\mathrm{~N}=241$ & $\mathrm{~N}=299$ \\
\hline
\end{tabular}

From Table 1 results, $\mathrm{ER}_{30}$ is higher in section 1 than in section 2. The observed lower $\mathrm{ER}_{30}$ in section 2 compared to section 1 may have implies higher density of mobile electric charges in section 2 than in section 1. This may be due to higher nutrients in section 2, majorly because the area had been uncultivated for some time, compared to section 1 which had been under continuous cultivation over years.

The observed higher $\mathrm{ER}_{90}$ in section 2 compared to section 1 may be because the area is intact and unexposed since it had been fallowed for years. This may have lead to much reduced leaching and percolation of topsoil nutrients and water into the deeper soil depth. Hence, density of mobile charges in the deeper soil depth is much reduced in section 2 compared to section 1 which had been constantly exposed.

\subsection{Distribution of Cassava tuber yield across the field}

Table 2: Basic statistical description of the tuber yield data

\begin{tabular}{|c|c|c|c|c|c|c|}
\hline \multirow{2}{*}{} & \multicolumn{3}{|c|}{ Section 1 $(\mathrm{N}=241)$} & \multicolumn{3}{|c|}{ Section $2(\mathrm{~N}=299)$} \\
\cline { 2 - 7 } & $\mathrm{N}_{\mathrm{T}}$ & $\mathrm{T}_{\mathrm{L}}$ & $\mathrm{T}_{\mathrm{W}}$ & $\mathrm{N}_{\mathrm{T}}$ & $\mathrm{T}_{\mathrm{L}}$ & $\mathrm{T}_{\mathrm{W}}$ \\
\hline Min & 1.00 & 0.11 & 1.00 & 1.00 & 0.11 & 1.51 \\
\hline Max & 20.00 & 0.85 & 2.68 & 20.00 & 0.59 & 3.55 \\
\hline Mean & 7.82 & 0.29 & 1.92 & 8.26 & 0.30 & 2.35 \\
\hline SD & 3.90 & 8.23 & 0.26 & 3.81 & 6.44 & 0.30 \\
\hline
\end{tabular}

Table 2 shows the distribution of tuber yield across the field. Generally, section 2 had the highest yield output with slightly lower variation compared to section 1 . This might be because the area had been uncultivated for some time, thus leading to accumulation of soil nutrients which may have aided higher yield production in the section, compared to section 1 which had been constantly cultivated.

\subsection{Relationship between Soil ER and tuber yield}

Table 3: Correlation analysis between ER and tuber yield data

\begin{tabular}{|c|c|c|}
\hline & $\mathrm{ER}_{30}$ & $\mathrm{ER}_{90}$ \\
\hline Yield parameter & $\mathrm{r}$ & $\mathrm{r}$ \\
\hline Average tuber length, $\mathrm{T}_{\mathrm{L}}(\mathrm{in} \mathrm{cm})$ & 0.04 & -0.02 \\
\hline Number of cassava tuber, $\mathrm{N}_{\mathrm{T}}$ & -0.05 & 0.02 \\
\hline Cassava tuber weight, $\mathrm{T}_{\mathrm{w}}$ (in $\mathrm{Kg}$ ) & $-0.84 * *$ & -0.03 \\
\hline Correlation is significant at 0.01 levels
\end{tabular}

Table 3 shows the results of correlation analysis. The results indicate that there is no significant relationship between ER and $\mathrm{T}_{\mathrm{L}}$ as well as between ER and $\mathrm{N}_{\mathrm{T}}$. Similarly, ER $\mathrm{R}_{90}$ had a very weak and negative insignificant correlation $(r=-0.03)$ with $\mathrm{T}_{\mathrm{W}}$ while $\mathrm{ER}_{30}$ had a strong negative significant correlation $(\mathrm{r}=-0.84)$ with $\mathrm{T}_{\mathrm{W}}$. This indicates that no relationship exists between $\mathrm{ER}_{90}$ and $\mathrm{T}_{\mathrm{W}}$ while significant relationship exists between $\mathrm{ER}_{30}$ and $\mathrm{T}_{\mathrm{W}}$. It therefore implies that as $\mathrm{ER}_{30}$ decreases, $\mathrm{T}_{\mathrm{W}}$ increases.

The strong correlation observed between $\mathrm{ER}_{30}$ and $\mathrm{T}_{\mathrm{W}}$ may be because most of the soil nutrients largely reside within the topsoil where $\mathrm{ER}_{30}$ was measured. The insignificant relationship between $\mathrm{ER}_{90}$ and tuber yield may be because the cassava plants' roots do not extend long enough to tap nutrients from the deeper soil depth where $\mathrm{ER}_{90}$ was measured. The formation of $\mathrm{T}_{\mathrm{L}}$ and $\mathrm{N}_{\mathrm{T}}$ may be due to another underlying soil factors which may have separate and individual significant influence on them, but do not have any significant effect on the measured ER or was not included among the soil properties averaged by ER.

Based on the correlation results, curve estimation analysis was performed to determine the best fit function that could be used to estimate $\mathrm{T}_{\mathrm{W}}$ from $\mathrm{ER}_{30}$.

Table 4: Curve estimation analysis for $\mathrm{ER}_{30}$ and $\mathrm{T}_{\mathrm{W}}$

\begin{tabular}{|c|c|c|c|}
\hline \multicolumn{4}{|c|}{ Independent variable: $\mathrm{ER}_{30}$, Dependent variable: $\mathrm{T}_{\mathrm{W}}$} \\
\hline Fitted function & $\mathrm{R}^{2}$ & Fitted function & $\mathrm{R}^{2}$ \\
\hline *Lorentz & 0.85 & Cubic & 0.78 \\
\hline *Gauss & 0.84 & Linear & 0.70 \\
\hline *Boltzmann & 0.82 & Spherical & 0.48 \\
\hline Exp (Decay) & 0.77 & Power & 0.73 \\
\hline Quadratic & 0.77 & Logarithmic & 0.73 \\
\hline
\end{tabular}

Table 4 shows the results of the curve estimation analysis. As shown on the table, Lorentz, Gauss and Boltzmann distributions are the best fit functions (with $\mathrm{R}^{2}=0.85,0.84$ and 0.82 , respectively) compared to other functions. Although their coefficient of determination, $\mathrm{R}^{2}$ differs slightly, yet there is no significant difference between them. Hence, ER can be used to estimate $\mathrm{T}_{\mathrm{W}}$ using Lorentz, Gauss and Boltzmann distributions.

Table 5: Results of Lorentz, Gauss and Boltzmann (non linear curve fit) distributions

Independent variable: $\mathrm{ER}_{30}$, Dependent variable: $\mathrm{T}_{\mathrm{W}}$

\begin{tabular}{|c|c|c|}
\hline \multicolumn{3}{|c|}{ Fitted distributions and their constants } \\
\hline $\begin{array}{c}\text { Lorentz } \\
\text { distribution } \\
\left(\mathrm{R}^{2}=0.85\right)\end{array}$ & $\begin{array}{c}\text { Gauss } \\
\text { distribution } \\
\left(\mathrm{R}^{2}=0.84\right)\end{array}$ & $\begin{array}{c}\text { Boltzmann } \\
\text { distribution } \\
\left(\mathrm{R}^{2}=0.82\right)\end{array}$ \\
\hline $\mathrm{y}_{\mathrm{o}}=1.59$ & $\mathrm{y}_{\mathrm{o}}=1.73$ & $\mathrm{~A}_{1}=2.77$ \\
\hline $\mathrm{x}_{\mathrm{c}}=338.25$ & $\mathrm{x}_{\mathrm{c}}=322.00$ & $\mathrm{~A}_{2}=1.70$ \\
\hline $\mathrm{w}=672.90$ & $\mathrm{w}=578.27$ & $\mathrm{w}=647.24$ \\
\hline $\mathrm{A}=1181.23$ & $\mathrm{~A}=679.33$ & $\mathrm{dx}=150.29$ \\
\hline
\end{tabular}

Table 5 gives the constants $\left(\mathrm{y}_{\mathrm{o}}, \mathrm{x}_{\mathrm{c}}, \mathrm{w}, \mathrm{A}, \mathrm{A}_{1}, \mathrm{~A}_{2}, \mathrm{dx}\right)$ and their associated values in Lorentz, Gauss and Boltzmann distribution equations shown below;

$$
\begin{aligned}
& \mathrm{T}_{\mathrm{w}}=\mathrm{y}_{0}+\left(\frac{2 \mathrm{~A}}{\pi}\right)\left[\frac{\mathrm{w}}{4\left(\mathrm{ER}_{30}-\mathrm{xc}\right)^{2}+\mathrm{w}^{2}}\right]= \\
& \mathrm{y}_{0}+\left(\frac{2 \mathrm{Aw}}{\pi}\right)\left[4\left(\mathrm{ER}_{30}-\mathrm{x}_{\mathrm{c}}\right)^{2}+\mathrm{w}^{2}\right]^{-1}(2.0) \\
& \mathrm{T}_{\mathrm{w}}=\mathrm{y}_{0}+\left(\frac{\mathrm{A}}{\mathrm{w}(\sqrt{\pi / 2})}\right) \exp \left[-2\left(\frac{\mathrm{ER}_{30}-\mathrm{x}_{\mathrm{c}}}{\mathrm{w}}\right)^{2}\right] \\
& \mathrm{T}_{\mathrm{w}}=\mathrm{A}_{2}+\left(\mathrm{A}_{1}-\mathrm{A}_{2}\right)\left[1+\exp \left(\frac{\mathrm{ER}_{30}-\mathrm{x}_{0}}{\mathrm{dx}}\right)\right]^{-1}
\end{aligned}
$$

Eqns (2.0), (3.0) and (4.0) represents Lorentz, Gauss and Boltzmann distribution equations, respectively. But,

\section{Volume 5 Issue 6, June 2016 www.ijsr.net}




\section{International Journal of Science and Research (IJSR) \\ ISSN (Online): 2319-7064}

Index Copernicus Value (2013): 6.14 | Impact Factor (2015): 6.391

$E R_{30}=(2 \pi a) R_{30}=2 \pi(0.3) R_{30}=$ $(1.89) R_{30}=(1.89) \frac{V_{30}}{I_{30}}(5.0)$

where ' $a$ ' in eqn (5.0) represents the soil depth $(0.3 \mathrm{~m})$ at which the soil resistivity is measured; $\mathrm{R}_{30}, \mathrm{~V}_{30}$ and $\mathrm{I}_{30}$ represents the average soil resistance, potential difference and electric current at the soil depth, respectively. Thus, using the results in Table 5 and eqns $(2.0)-(5.0), E R_{30}$ can be used to predict $\mathrm{T}_{\mathrm{W}}$ with the aid of eqns $(6.0)-(8.2)$.

$\mathrm{T}_{\mathrm{w}}=1.59+(505,951.41)\left[4\left(\mathrm{ER}_{30}-338.25\right)^{2}-\right.$

672.902-1 (Lorentz distribution) (6.0)

$\mathrm{T}_{\mathrm{w}}=1.59+(505,951.41)\left[4\left(1.89 \mathrm{R}_{30}-338.25\right)^{2}-\right.$

672.902-1 (Lorentz distribution) (6.1)

$\mathrm{T}_{\mathrm{w}}=1.59+(505,951.41)\left[4\left(\frac{1.89 \mathrm{~V}_{30}}{\mathrm{I}_{30}}-338.25\right)^{2}-\right.$

672.902-1 (Lorentz distribution) (6.2)

$\mathrm{T}_{\mathrm{w}}=1.73+(0.94) \exp \left[-2\left(1.73 \times 10^{-3} \mathrm{ER}_{30}-0.56\right)^{2}\right]$

(Gauss distribution) (7.0)

$\mathrm{T}_{\mathrm{w}}=1.73+(0.94) \exp \left[-2\left(3.27 \times 10^{-3} \mathrm{R}_{30}-0.56\right)^{2}\right]$

(Gauss distribution) (7.1)

$\mathrm{T}_{\mathrm{w}}=1.73+(0.94) \exp \left[-2\left(\frac{3.27 \times 10^{-3} \mathrm{~V}_{30}}{\mathrm{I}_{30}}-0.56\right)^{2}\right]$

(Gauss distribution) (7.2)

$\mathrm{T}_{\mathrm{w}}=1.70+(1.07)\left[1+\exp \left(6.65 \times 10^{-3} \mathrm{ER}_{30}-4.31\right)\right]^{-1}$ (Boltzmann distribution) (8.0)

$\mathrm{T}_{\mathrm{w}}=1.70+(1.07)\left[1+\exp \left(12.57 \times 10^{-3} \mathrm{R}_{30}-4.31\right)\right]^{-1}$ (Boltzmann distribution) (8.1)

$\mathrm{T}_{\mathrm{w}}=1.70+(1.07)\left[1+\exp \left(\frac{12.57 \times 10^{-3} \mathrm{~V}_{30}}{\mathrm{I}_{30}}-4.31\right)\right]^{-1}$

(Boltzmann distribution) (8.2)

The graphs of $\mathrm{ER}_{30}-\mathrm{T}_{\mathrm{W}}$ relationships are given by Figs. 3 5. Careful study of the graphs showed that field areas with $\mathrm{ER}_{30} \geq 1,500 \Omega \mathrm{m}$ produced the least yield $\left(\mathrm{T}_{\mathrm{W}}<2.00 \mathrm{Kg}\right)$. This implies that such areas are not suitable for quality cassava productivity. If in case such areas must be used, then intense soil management practices must be conducted in order to have quality and optimum yield from those areas.

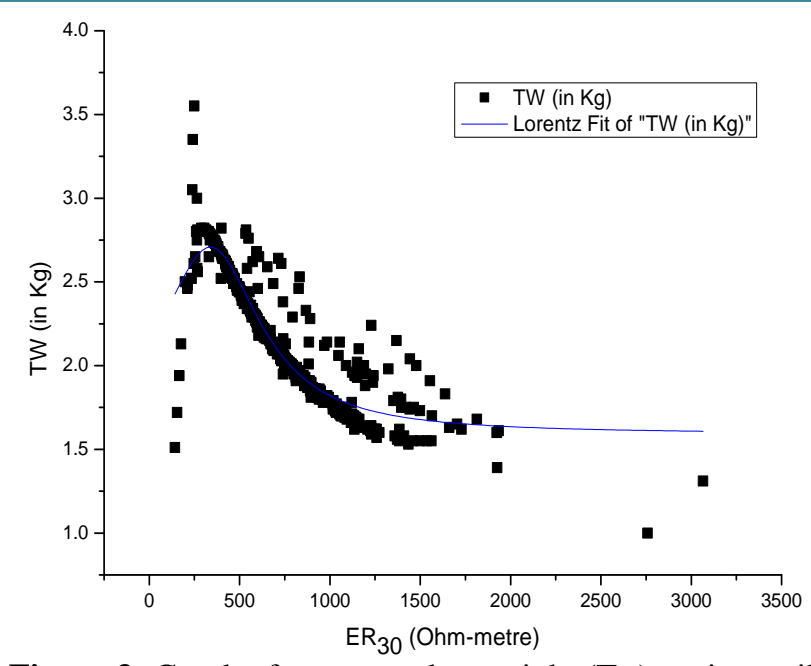

Figure 3: Graph of cassava tuber weight $\left(\mathrm{T}_{\mathrm{W}}\right)$ against soil resistivity $\left(\mathrm{ER}_{30}\right)$ fitted to Lorentz distribution.

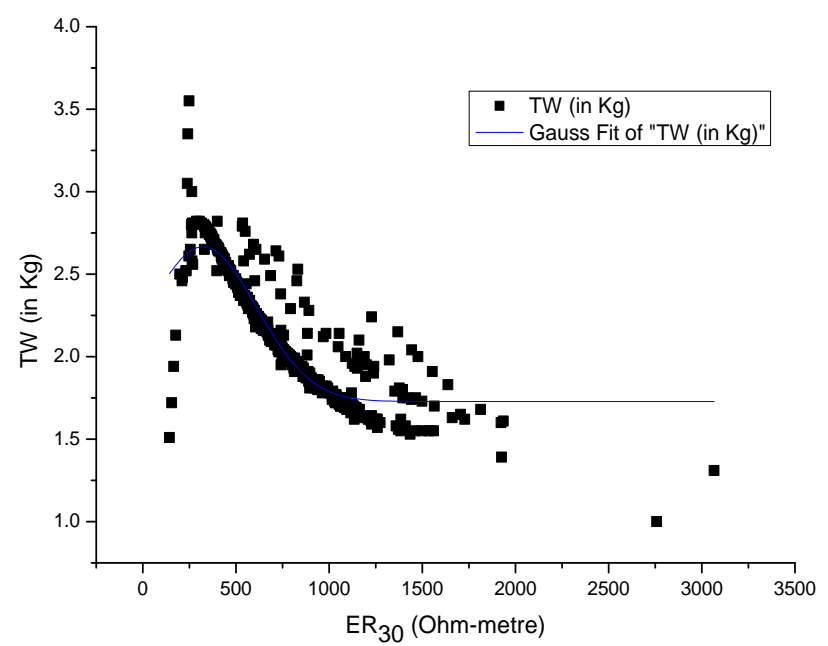

Figure 4: Graph of cassava tuber weight $\left(\mathrm{T}_{\mathrm{W}}\right)$ against soil resistivity $\left(\mathrm{ER}_{30}\right)$ fitted to Gauss distribution.

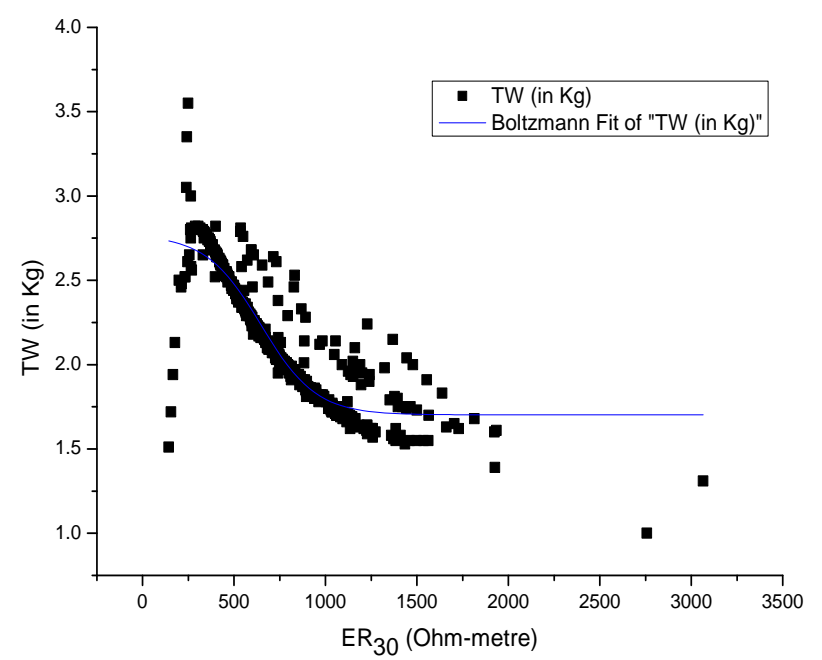

Figure 5: Graph of cassava tuber weight $\left(\mathrm{T}_{\mathrm{W}}\right)$ against soil resistivity $\left(\mathrm{ER}_{30}\right)$ fitted to Boltzmann distribution.

\section{Conclusion}

The results gathered from this study indicated that:

1) Fallowed areas exhibited lower $\mathrm{ER}_{30}$ and higher $\mathrm{ER}_{90}$ than constantly cultivated areas.

Volume 5 Issue 6, June 2016 www.ijsr.net 


\section{International Journal of Science and Research (IJSR) \\ ISSN (Online): 2319-7064}

Index Copernicus Value (2013): 6.14 | Impact Factor (2015): 6.391

2) Field areas with lower $\mathrm{ER}_{30}$ values exhibited relatively higher tuber yield (especially in $\mathrm{T}_{\mathrm{W}}$ ) than areas with higher $\mathrm{ER}_{30}$ values.

3) There is no significant relationship between ER and $T_{L}$ as well as between ER and $\mathrm{N}_{\mathrm{T}}$.

4) Tuber weight, $T_{W}$ was significantly influenced by $E_{30}(r$ $=-0.84)$ rather than $\mathrm{ER}_{90}(\mathrm{r}=-0.03)$.

5) Soil $\mathrm{ER}_{30}$ between 250 and $500 \Omega \mathrm{m}$ effectively support higher $\mathrm{T}_{\mathrm{W}}$ yield than $\mathrm{ER}_{30}>500 \Omega \mathrm{m}$.

6) Field areas with $\mathrm{ER}_{30} \geq 1,500 \Omega \mathrm{m}$ requires intense soil management practices in order to have optimum yield.

7) Soil $E_{30}-T_{W}$ relationship was best fitted to Lorentz $\left(R^{2}\right.$ $=0.85)$, Gauss $\left(R^{2}=0.84\right)$ and Boltzmann $\left(R^{2}=0.82\right)$ distributions. Therefore, $\mathrm{ER}_{30}$ can effectively estimate $\mathrm{T}_{\mathrm{W}}$ using the following equations;

$\mathrm{T}_{\mathrm{w}}=1.59+(505,951.41)\left[4\left(\mathrm{ER}_{30}-338.25\right)^{2}-\right.$

672.902-1 (Lorentz distri.)

$\mathrm{T}_{\mathrm{w}}=1.73+(0.94) \exp \left[-2\left(1.73 \times 10^{-3} \mathrm{ER}_{30}-0.56\right)^{2}\right]$ (Gauss distri.)

$\mathrm{T}_{\mathrm{w}}=1.70+(1.07)\left[1+\exp \left(6.65 \times 10^{-3} \mathrm{ER}_{30}-4.31\right)\right]^{-1}$ (Boltzmann distri.)

\section{Future Scope}

Similarly studies which use ER for cassava yield prediction (including other cassava varieties) and on other soil types should also be conducted in order to further assess and expand the predictive ability of ER on cassava plants' yields. Despite the quality of information obtained from this study, it is limited only to tuber yield prediction of cassava (TMS 98/0505) variety planted on sandy-loam soil.

However, this study provides for farmers and researchers objective information which can be used to predict cassava tuber weight directly from ER of soil, assess the quality of the soil nutrients and delineate specific management zones without having to dig the soil for sample collection and, undergo laborious and expensive laboratory analysis.

\section{Acknowledgement}

The researchers would like to thank Tertiary Education Trust Fund (TETFUND), Nigeria for financial support which helped the completion of this study.

\section{References}

[1] V. I. Adamchuk, and P. J. Jasa, "On-the-go-vehicle Based Soil sensor," University of Nebraska Cooperative Extension, $\quad$ EC $\quad-\quad 002 \quad 0 \quad 0178$. http://ianrpubs.unl.edu/fieldcrops/ec178.pdf. (accessed 12/05/2013).

[2] W. Aimrun, M. S. M. Amin, M. Rusnam, D. Ahmad, M. M. Hanafi and A. R. Anuar, "Bulk Soil Electrical Conductivity as an Estimator of nutrients in the Maize Cultivated Land," European Journal of Scientific Research, vol. 31 (1), pp. 37 - 51, 2009.

[3] W. Aimrun, M. S. M. Amin, M. H. Ezrin, and M. Mastura, "Paddy soil properties and yield characteristics based on apparent electrical conductivity zone delineation for a humid tropical rice farm," African journal of agricultural research, vol. 6 (23), pp. 5339 5350, 2011.

[4] S. A. Al Hagrey, "Electrical resistivity imaging of tree trunks," Near Surface Geophysics, vol. 4, no. 3, pp. 179 $-187,2006$.

[5] M. Amato, B. Basso, G. Celano, G. Bitella, G. Morelli, and R. Rossi, "In situ detection of tree root distribution and biomass by multi-electrode resistivity imaging," Tree Physiology, 28, pp. 1441 - 1448, 2008.

[6] M. Amato, G. Bitella, R. Rossi, J. A. Gómez, S. Lovelli, and J. J. F. Gomes, "Multi-electrode 3D resistivity imaging of alfalfa root zone," European Journal of Agronomy, vol. 31, no. 4, pp. 213 - 222, 2009.

[7] F. André, C. van Leeuwen, S. Saussez, R. Van Durmen, P. Bogaert, D. Moghadas, L. De Rességuier, B. Delvaux, H. Vereecken, and S. Lambot, "Highresolution imaging of a vineyard in south of France using ground-penetrating radar, electromagnetic induction and electrical resistivity tomography," $J$. Appl. Geophys., vol. 78, 113 - 122, 2012.

[8] B. Basso, M. Amato, G. Bitella, R. Rossi, A. Kravchenko, L. Sartori, L. M. Carvahlo, and J. Gomes, "Two-dimensional spatial and temporal variation of soil physical properties in tillage systems using electrical resistivity tomography," Agronomy J., 102, 440, 2010.

[9] A. Besson, I. Cousin, A. Samouelian, H. Boizard, G. Richard, "Structural heterogeneity of the soil tilled layer as characterized by 2-D electrical resistivity surveying," Soil Tillage Res., vol. 79, pp. 239 - 249, 2004.

[10] A. Besson, I. Cousin, H. Bourennane, B. Nicoullaud, C. Pasquier, G. Richard, "The spatial and temporal organization of soil water at the field scale as described by electrical resistivity measurements," European Journal of Soil Science, vol. 61, pp. 120 - 132, 2010.

[11] L. Brillante, B. Bois, O. Mathieu, V. Bichet, D. Michot, and J. Lévêque, "Monitoring soil volume wetness in heterogeneous soils by electrical resistivity. A field based pedotransfer function," J. Hydrol., vol. 516, pp. $55-66,2014 a$.

[12] L. Brillante, O. Mathieu, B. Bois, C. Van Leeuwen, and J. Leveque, "The use of soil Electrical Resistivity to monitor plant and soil water relationships in vineyards," Soil journal, vol. 1, pp. 273 - 286, 2015.

[13] Carlos Mauricio Paglis, "Application of ER tomography for detecting root biomass in Coffee Trees," International journal of geophysics, article ID 383261, 2013.

[14]D. L. Corwin and S. M. Lesch, "Apparent soil Electrical Conductivity measurements in Agric.," J.Computers and Electronics in Agriculture, vol. 46, issues 1 - 3, pp. $11-43,2005$.

[15] C. Doussan and S. Ruy, "Prediction of unsaturated soil hydraulic conductivity with electrical conductivity," Water Resour. Research., vol. 45, pp. 1 - 12, 2009.

[16] R. Gebbers, E. Lück, M. Dabas and H. Domsch. "Comparison of instruments for geoelectrical soil mapping at the field scale," Near Surface Geophysics, vol. 7 (3), pp. 179 - 190, 2009.

[17]Z. Z. Hadzick, A. K. Guber, Y. A. Pachepsky, and R. L. Hill, "Pedotransfer functions in soil electrical resistivity estimation," Geoderma, vol. 164, pp. 195 - 202, 2011. 


\section{International Journal of Science and Research (IJSR) \\ ISSN (Online): 2319-7064}

Index Copernicus Value (2013): 6.14 | Impact Factor (2015): 6.391

[18] I. S. Jakalia, A. A. Aning, K. Preko, N. Sackey, S. K. Danuor, "Implications of soil resistivity measurements using the electrical resistivity method: A case study of a Maize Farm under different soil preparation modes at KNUST agricultural research station, Kumasi," International Journal of Scientific and Technology Research, vol. 4 (1): 9 - 18, 2015.

[19] C. K. Johnson, R. A. Eigenberg, J. W. Doran, B. J. Wienhold, and B. L. Eghball, "Status of soil electrical conductivity studies by central state research," Trans. $A S A E$, vol. 48 (3), pp. 979 - 989, 2005.

[20] S. M. Lesch, D. L. Corwin, and D. A. Robinson, "Apparent soil electrical conductivity mapping as an agricultural management tool in arid zone soils," Comput. Electronics Agric., vol. 46, 351 - 378, 2005.

[21]Muraina Z. Mohammed and Isaac R. Ajayi, "Geoelectric evaluation of subsoil for optimum cocoa yield in parts of Ondo state, southwestern, Nigeria," Civil and Environmental Research, vol. 6 (1): 1 - 8, 2014.

[22] V. V. Navarkhele, "Measurement of physical-chemical properties of soils for jawar crop," Journal of chemical and pharmaceutical research, vol. 7 (2): 314 - 323, 2015.

[23] G. U. Nnaji, "Changes in Physical properties of Soil under Cassava (Manihot Esculenta Crantz) Monocropping and Organic waste Amendments," Natural and Applied Sciences Journal, vol. 10 (1), 2009.

[24] C. N. Nwankwo, D. O. Ogagarue and F. O. Ezeoke, "Investigation of variation in resistivity with depth and soil dielectric constant in parts of Rivers state, Southern Nigeria," British Journal of Applied Science and Technology, vol. 3 (3): 452 - 461, 2013.

[25] S. O. Ojeniyi, S. A. Adejoro, O. Ikotun, and O. Amusan, "Soil and plant nutrient composition, growth and yield of cassava as influenced by integrated application of NPK fertilizer and poultry manure," New York Science Journal, vol. 5 (9), pp. 62 - 68, 2012.

[26] R. Rossi, M. Amato, G. Bitella, R. Bochicchio, J. J. Ferreira Gomes, S. Lovelli, E. Martorella, and P. Favale, "Electrical resistivity tomography as a nondestructive method for mapping root biomass in an orchard," European J. Soil Sci., vol. 62(2), 206 - 215, 2011.

[27] R. Rossi, A. Police, M. P. Diago, M. Oliveira, B. Milllan, G. Bitella, M. Amato, and J. Tardaguila, "Using an Automatic Resistivity Profiler Soil Sensor On-The-Go in Precision Viticulture," Sensors, vol. 13: $1121-1136,2013$.

[28] A. Samouëlian, I. Cousin, A. Tabbagh, A. Bruand, and G. Richard, "Electrical resistivity survey in soil science: a review," Soil and Tillage Research, vol. 83, no. 2, pp. 173 - 193, 2005.

[29] Torleif Dahlin, Pär Aronsson, and Mats Thörnelöf, "Soil resistivity monitoring of an irrigation experiment," Near surface geophysics, vol. 12, pp. 35 - 43, 2014.

[30] J. Triantafilis, and S. M. Lesch, "Mapping clay content variation using electromagnetic induction techniques," Comput. Electronics Agric., vol. 46, 203 - 237, 2005.

\section{Author Profile}

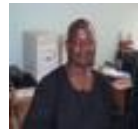

Emmanuel Oluwagbemi Joshua, $\mathrm{PhD}$ is a senior lecturer in the department of Physics, Solid Earth Physics (Geophysics) unit, University of Ibadan, Oyo state, Nigeria.

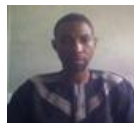

Adewunmi Olanrewaju Mokuolu, is a lecturer in the department of Physics, Federal College Education, Abeokuta, Ogun State, Nigeria. 